with 0.8 per cent gamma-BHC, showed a mortality corresponding to the effect of 0.2 per cent gamma$\mathrm{BHC}$ and two passages for our normal strain. We found that continued tests at intervals of six weeks still showed significant resistance against gamma.BHC which varied between 20 and 40 times.

In the meantime, we received a sample of bedbugs from a different part of the country which also showed resistance, although to a lesser degree, namely, 5-10 times.

Bedbugs from Tiberias, which we received as a third consignment, and which have also been tested, showed an increased resistance of 20 times to gamma. BHC. These facts are of interest as we have seen no reference hitherto of resistance of Cimex lectularius to gamma-BHC.

$$
\text { R. CWILICH }
$$

$$
\text { G. G. MER }
$$

Malaria Research Station

of the Hebrew University,

Rosh Pinah, Israel.

\section{Temperature Preference of Grylloblatta campodeiformis Walker}

DURING the field season of 1956, I was able to collect a number of living Grylloblatta campodeiformis Walker, some of which I have maintained in the laboratory. The insects are held in individual plastic boxes almost filled with rotten wood and kept in a refrigerator at $4-5^{\circ} \mathrm{C}$. After six months, six nymphs remain active and apparently in good condition. They are fed every two or three weeks on Drosophila larvæ, and water is added to keep the rotten wood very moist.

These insects have been tested for temperature preference in a circular gradient apparatus to be described elsewhere. Since preliminary tests showed that the insects would not enter air at less than saturation regardless of temperature, all tests were run with saturated air being slowly circulated from the hot to the cool parts of the gradient in such a way that condensation was taking place in all parts of the apparatus.

Each insect was exposed for five minutes and its position recorded at 15 -sec. intervals. Five runs with the entire series of insects were made and the mean number of 15-sec. intervals passed at each of a series of temperatures is shown in Table 1. The temperatures given represent the centres of zones in a continuous gradient. Though the gradient extended to both higher and lower temperatures than those given, the insects did not leave the parts of the gradient represented in Table 1.

The preference is centred on $1^{\circ} \mathrm{C}$. This finding supports Mills and Pepper's suggestion that Grylloblatta do not hibernate ${ }^{1}$ but rather move deep into the soil. Certainly, the insects are photo-nega. tive $^{2}$, avoid air at less than saturation, and have an exceedingly low temperature preference as well as an ability to move well at temperatures down to $-5 \cdot 6^{\circ} \mathrm{C} .{ }^{8}$. This combination of reactions would result in the insects moving into the soil at times of strong surface
Table 1. NUMBER OF 15-SkC. INTERVALS SPENT IN VARIOUS ZONES OF THMPRRATURE IN A CIROULAR TEMPRRATURE GRADIRNT (TEM-

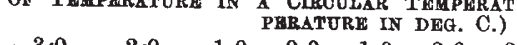

$\begin{array}{cccccccccc}-3 \cdot 0 & -2 \cdot 0 & -1 \cdot 0 & 0 \cdot 0 & 1 \cdot 0 & 2 \cdot 0 & 3 \cdot 0 & 4 \cdot 0 & 5 \cdot 0 & 6 \cdot 0\end{array}$

heating or cooling. I would suggest that this provides an explanation for the frequent failure of summer collecting as well as the success of autumn collecting ${ }^{1}$. An account of collecting experience which supports this interpretation is being published elsewhere.

206 Osborn Zoological Laboratory,

$$
\text { W. R. HENSON }
$$

Yale University,

New Haven, Conn.

Jan. 3.

${ }^{1}$ Mills, H. B., and Pepper, J. H., Ann. Ent. Soc. Amer., 30, 269 (1937).

"Ford, N., Canad. Ent., 58, 66 (1926).

${ }^{3}$ Edwards, G. A., and Nutting, W. L., Psyche, 57, 33 (1950).

\section{Population Studies on Three Species of Cladocera}

IN a biometrical study of three species of Cladocera taken from eight lagoons of the Province of Buenos Aires, in which several measurements were taken of about 940 specimens, some interesting events were recorded. Bosmina obtusirostris Sars offers a great variation in measurements with respect to the composition of the population (young and adult individuals taken at random). For the same date, in different years, there can be differences more accentuated than the seasonal ones. For the same date, two different lagoons have similar or distinct populations according to the measurements considered. Different parts of the same biotope have very similar populations if only females with eggs are considered. With respect to the coefficient of variation $V$, which for the normal cases oscillates between 4 and 10, such high numbers as 21 for the caudal height and length of the mucron have been recorded. Measurements of the antennula are very constant. During the cold months of the year an increment in the height and in the length is noted ; but this increment was not recorded in caudal height or the lengths of the mucron and antennula. Therefore, there is no relationship between seasons and proportion of females with eggs. These facts, and some others, point to a singular difference from observations made in European species of the same genus ${ }^{1}$.

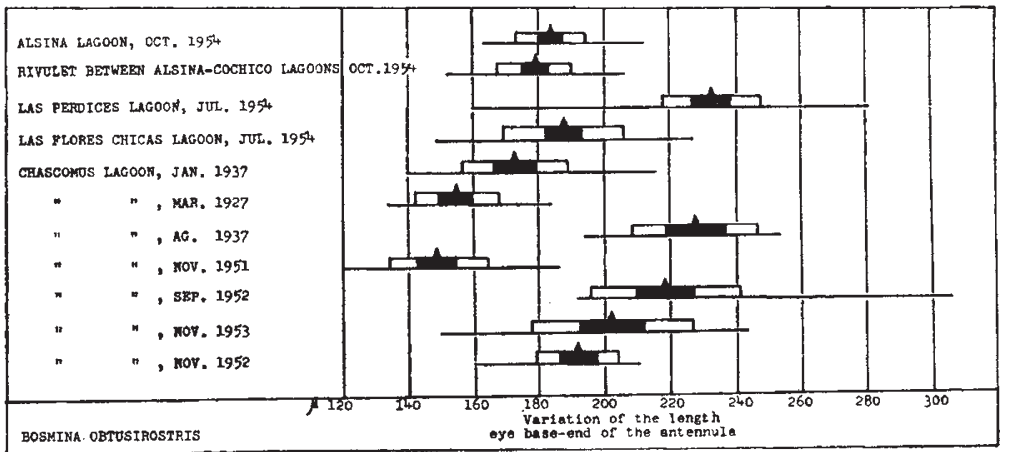

Fig. 1. The horizontal line represents the range of variation, with its corresponding arithmetical mean indicated by the arrow-head. The black rectangle covers twice the standard error to each side of the mean. The whole rectangle, including the white and black parts, represents a standard deviation to each side of the mean (ref. 4) 